\title{
RELAÇÃO FAMÍLIA-ESCOLA: O ESTADO DA ARTE NA PÓS-GRADUAÇÁO BRASILEIRA
}

\author{
FAMILY-SCHOOL RELATIONSHIP: THE STATE OF ART IN THE \\ BRAZILIAN POST-GRADUATION
}

\begin{abstract}
Andreza Maria de Lima
Doutora em Educação pela Universidade Federal de Pernambuco. Professora do Instituto Federal de Educaçấo, Ciência e Tecnologia de Pernambuco, Campus Pesqueira. PE - Brasil andrezaml@hotmail.com
\end{abstract}

Laêda Bezerra Machado

Doutora em Educação pela Universidade Federal do Rio Grande do Norte. Professora da Universidade Federal de Pernambuco. PE - Brasil laedaor@gmail.com

Resumo: A temática da relação família-escola vem ocupando maior espaço na produção científica no Brasil. Neste artigo, analisamos resumos de teses e dissertaçóes brasileiras sobre essa relaçáo produzidas no período 2004-2013 e reconstituímos a história dessa relação com autores como Cunha (2003) e Faria Filho (2000). O estudo, qualitativo, é do tipo Estado da Arte. Foram consultados os bancos de dados do Grupo Observatório Sociológico Família-Escola da Universidade Federal de Minas Gerais; do Programa de Pós-Graduaçáo em Família e Sociedade Contemporânea da Universidade Católica de Salvador; e de teses e dissertaçóes da Coordenação de Aperfeiçoamento de Pessoal de Nível Superior. Os resumos localizados (I I2) foram mapeados em relação a objetivos, referenciais teóricos, opçóes metodológicas e resultados. Para análise, utilizamos a Técnica de Análise de Conteúdo Categorial Temática, resultando na construção de três categorias: Relação família-escola e estratégias educativas familiares; Relação famíliaescola e fenômenos socio-escolares e Relação família-escola: fenômenos e/ou aspectos dessa relação. Em relação aos referenciais teóricos, menos da metade dos resumos os menciona; quanto a percurso metodológico e resultados das pesquisas, muitas informações também estavam ausentes. Apesar disso, resultados de algumas pesquisas indicam certa resistência de professores a configuraçóes familiares diferentes da tradicional e para a influência dessa resistência na relação com a família e/ou o trabalho docente, e outras desconstroem a ideia generalizada de que as famílias de alunos de escola pública são desestruturadas. Apontamos para a necessidade de outras pesquisas sobre a temática, pois há ainda vários aspectos a aprofundar, e para a importância de os resumos serem mais completos.

Palavras-chave: Escola. Família. Pesquisa. Pós-Graduação. 
Aвstract: The family-school relationship has occupied more space in scientific production in Brazil. In this article, we analyze summaries of Brazilian theses and dissertations on the family-school relationship produced in the period 2004-2013. We reconstruct the history of this relationship in Brazil from authors such as Cunha (2003) and Faria Filho (2000). The study, of a qualitative nature, is of the State of Art type. For the location of the works, we consulted three databases: the thesis bank and dissertations on the family-school relationship of the Observatory Family-School Sociology of the Federal University of Minas Gerais (OSFE / UFMG); the database of the Postgraduate Program in Family and Contemporary Society of the Catholic University of Salvador (UCSal); and the thesis and dissertation bank of the Coordination for the Improvement of Higher Education Personnel (CAPES). The localized abstracts (I I2) were mapped in relation to objectives, theoretical references, methodological options (empirical field, participants, collection and analysis procedures) and results. For analysis, we used the Thematic Categorical Content Analysis Technique, resulting in the construction of three categories: family-school relationship and family educational strategies; Family-school relationship and socio-school phenomena and Family-school relationship: phenomena and / or aspects of this relationship. Regarding the theoretical references, less than half of the abstracts mentioned the authors who supported the studies. With regard to the methodological path and the results of the research, much information was also absent. Nevertheless, we have found some research that points to a certain resistance of teachers with different family configurations from the traditional one and the influence of this resistance in the relation with the family and / or the teaching work; and others that deconstruct the widespread view that the families of public school students are disorganized. Finally, we point out the need for further research on the subject, as there are still several aspects to be explored; as well as the importance of the abstracts being carefully prepared by the researchers.

Keywords: School. Family. Researche. Postgraduate Studies.

\section{Introdução}

A família, por diversas razões, é regularmente tema de conversas e notícias em uma série infindável de lugares sociais. No âmbito escolar, ganha ainda maior visibilidade, tornando-se assunto de conversa e discussão no cotidiano das instituiçóes. Na atualidade, no mundo e no Brasil, existe um intenso processo de aprofundamento dos laços que unem essas duas instâncias de socialização, com a escola reconhecendo na família um parceiro importante para a realização de suas finalidades.

Segundo Nogueira (2006), diversos autores do campo da Sociologia têm ressaltado a existência de uma nova divisão do trabalho educativo entre a escola e a família. A instituição escolar está, cada vez mais, extrapolando suas funçóes de desenvolvimento intelectual para se ocupar tam- 
bém de dimensóes corporais, morais e emocionais da formação do aluno, e a família está intervindo de modo crescente nos processos pedagógicos (DAYRELL et al., 20I2). Essas instâncias estão enfrentando conflitos de funções sociais que se complexificam na relação entre as famílias pobres e a escola pública.

Durante a década de 1990, o diagnóstico de que as famílias dos estudantes de escola pública são 'desestruturadas' foi massificado (CRUZ; SANTOS, 2008). Nas últimas décadas, a universalização do acesso à escola pública desestabilizou a cultura tradicional da escola e dos professores, pois a absorção das classes populares entrou em conflito com o modelo de escola elitizada. Nesse cenário, os professores responsabilizam as famílias dos estudantes pelo fracasso na aprendizagem formal e pela não aquisição de regras básicas de convivência (CRUZ; SANTOS, 2008). Goldani (1993) afirma que a desestruturação familiar é um mito decorrente do modelo de família patriarcal, que foi reforçado pelas transformaçóes ocorridas na sociedade. A autora propóe uma interpretaçáo alternativa ao aludido declínio familiar, ao mostrar que as famílias pobres, sobretudo as urbanas, vivenciam um processo de formação, expansão e contração em um quadro de precariedade de condiçôes de vida.

Neste artigo, parte de uma pesquisa de doutorado em educaçáo que analisa as representaçóes sociais das famílias dos estudantes de escola pública construídas por professoras dos anos iniciais do Ensino Fundamental da Rede Municipal de Ensino do Recife-PE, analisamos resumos de teses e dissertaçooes brasileiras sobre a relação família-escola produzidas no período 2004-2013. Reconhecemos o resumo como um dos gêneros do discurso da esfera acadêmica, com a finalidade de divulgar com mais abrangência os trabalhos produzidos nessa esfera. Nesse sentido, cada resumo deve contemplar o ciclo de uma pesquisa: introdução, objetivo, referencial teórico, metodologia e resultados/conclusôes. Para Ferreira (2002), os resumos devem trazer, enquanto gênero do discurso, um conteúdo temático - apresentar aspectos das pesquisas a que se referem; uma certa padronização quanto à estrutura composicional anunciar o que se pretendeu investigar, o percurso metodológico e os resultados alcançados; e um estilo verbal marcado por uma linguagem concisa e descritiva. 
Trata-se de um estudo de natureza qualitativa e caráter exploratório e bibliográfico, comumente denominado 'Estado da Arte' ou 'Estado do Conhecimento', estudos que decorrem da revisão da literatura. Conforme Alves-Mazzotti (2002), a revisão de literatura tem dois objetivos: a construção da contextualização do problema de pesquisa e a análise das possibilidades presentes na literatura para a construção do referencial teórico. Estudos do tipo Estado da Arte permitem o aprofundamento da análise sobre o objeto de estudo, por possibilitarem estabelecer relaçóes com produçóes anteriores, identificando temáticas recorrentes e apontando novas perspectivas de estudo (VOSGERAU; ROMANOWSKI, 20I4). Ferreira (2002) afirma que as pesquisas do tipo Estado da Arte buscam mapear e discutir certa produção acadêmica em diferentes campos, buscando evidenciar quais aspectos e dimensôes de um tema são privilegiados em diferentes épocas e lugares e de que formas e em que condiçóes têm sido produzidos os trabalhos acadêmicos. Romanowski e Ens (2006) afirmam que essas pesquisas possibilitam uma visão geral do que vem sendo produzido na área, favorecendo uma ordenação da produção que permite aos interessados perceber a evolução do conhecimento.

Nogueira, Romanelli e Zago (20II) ressaltam que a temática relação família-escola envolve uma problemática ampla, suscetível de ser abordada a partir de diferentes campos disciplinares. Tal fato, conforme destacam, dispersa a produção, dificultando sua organização e classificação. Na ocasião da primeira edição do livro, em 2000, os autores lamentavam não termos um estado da arte das diferentes tendências temáticas e teórico-metodológicas dos estudos que abordam a relação família-escola no Brasil. Em outra obra, publicada uma década após a primeira (NOGUEIRA; ROMANELLI; ZAGO, 20I3), os autores a introduzem com um artigo de Geraldo Romanelli que apresenta o levantamento crítico da produção brasileira sobre a temática em periódicos disponíveis em meio eletrônico entre 1997 e 201 I. No entanto, o material fica circunscrito à Sociologia da Educação.

Zago (20I2), apoiada em uma série de demandas sobre a relação família-escola, afirmou que essa temática vem ocupando maior espaço no campo da Educação; porém, também reforçou que ainda não tínhamos uma análise sistematizada que indicasse o estado da produção do conhecimento sobre a relação família-escola no Brasil. 


\section{Relação famílias (pobres) e escola (pública): o caso brasileiro em perspectiva histórica}

$\mathrm{Na}$ história da educação moderna a escola é considerada como instituição que procura formar a criança e o adolescente, tendo em vista o cidadão adulto (CUNHA, 2003). No Brasil, durante o século XIX, a escola se fortalece como espaço privilegiado de formação de futuras geraçôes. Nesse processo, desloca outras instituiçóes, dentre elas a família, de seus lugares tradicionais de socialização, considerando-as, na maioria das vezes, "[...] incapazes de bem educar diante de uma sociedade que se urbaniza e se complexifica, que supóe novas dinâmicas e padrôes de comportamento." (FARIA FILHO, 2000, p. 44) Nesse período, e ainda por décadas, a oferta de escolarização era escassa no país, destinada a poucos. Entretanto, de acordo com Faria Filho (2000), já nas primeiras décadas do século XX o afastamento da família em relação à escola passa a ser uma preocupação dos professores e de outros agentes da educação. Partindo da premissa de que a participação das famílias era necessária ao processo escolar, afirmavam que as famílias demonstravam um profundo desinteresse e despreparo para lidar com o assunto, principalmente as famílias pobres. Por isso, era necessário o desenvolvimento de açóes destinadas a reaproximar a família da escola.

No entanto, tais açôes revelam "[...] uma intenção colonizadora da escola em relação à família, entendida esta tarefa como um momento fundamental da ação reformista da escola em face da realidade social mais ampla [...]" (FARIA FILHO, 2000, p. 45) Segundo Cunha (2003, p. 450), a escola, paulatinamente, incorpora saberes científicos em oposição aos saberes domésticos, tornando-se, assim, uma instância de poder, pois “[...] o discurso da ciência [...] caracteriza-se por desqualificar a família no tocante à educação do corpo e do espírito."

Portanto, o tema não diz respeito unicamente a mecanismos de discriminação entre camadas sociais, pois se trata de um fenômeno mais sutil e difícil de ser abolido: a posição ocupada pela escola diante das famílias. Ocorre que tal postura é mais acentuada em relação às famílias pobres.

No Brasil, tais ações de teor normativo são fortalecidas com o movimento escolanovista, que surge no final do século XIX e ganha maior expressividade nas décadas de 20 e 30 do século XX. Seu ideário educacional conclama o poder público a tomar iniciativas com o objetivo de construir 
uma escola acessível a setores não pertencentes à elite da sociedade. No contexto desse ideário surge a Associação Brasileira de Educação (ABE), que propóe um maior relacionamento entre escola e família. Por meio dessa Associação, surge um setor destinado à educação familiar, a Seção de Cooperação da Família, à qual cabia, segundo Campos (20II, p. 6, grifo da autora), "[...] propiciar a participação e a aproximação dos pais com a instituição escolar; caso contrário, o objetivo de 'instruir e civilizar' a população por meio da educação não se implementaria [...]”

Em 1932, os escolanovistas promulgam o Manifesto dos Pioneiros da Educação Nova, redigido por Fernando de Azevedo e assinado por vinte e seis educadores, com o significativo subtítulo $A$ reconstrução educacional do Brasil - ao povo e ao governo. O movimento, representado no texto, se propóe a retirar a escola e os programas de ensino dos quadros de segregaçáo social vigentes, adequando a instituiçáo escolar à nova sociedade urbanoindustrial emergente, dado que

Nesse empenho normalizador, a família continuou sendo alvo privilegiado, pois se sabia que nada de produtivo e duradouro poderia ser feito com a criança na escola se não houvesse a receptividade aos procedimentos pedagógicos no ambiente doméstico. A família, portanto, devia enquadrar-se, ou ser enquadrada, nos princípios ditados pelo discurso educacional renovador. Isso se aplicava, em tese, a todas as famílias, independentemente da camada social a que pertencessem. Tal raciocínio era justificado pela recorrência a uma concepção de história e de sociedade mediante os avanços do modo capitalista de produção: a nova configuração do mundo do trabalho impedia as famílias de educarem corretamente seus filhos. (CUNHA, 2003, p. 457)

Mais do que nunca, ainda de acordo com Cunha (op.cit., p. 458), coube à escola lutar contra a família, pois o discurso escolanovista continha "[...] argumentos aparentemente irrefutáveis, posto que assentados nas crenças científicas." Considerando que a principal meta da escola renovada era educar crianças e jovens visando a um ideal de sociedade, era preciso adequar a esse ideal "[...] todos aqueles que constituíssem obstáculo ao 
desenvolvimento social.” (op.cit., p. 459) Esse discurso ganhava contornos mais bem definidos quando abordava especificamente o 'problema' das famílias pobres. Por isso, tornava-se imperativo superar o estado em que se encontravam essas famílias.

A ênfase numa educação fundamentada em conhecimentos de base científica, advindos da pedagogia escolanovista, alcançou seu auge durante a década de 1950. Isso porque o discurso desse pensamento educacional é articulado em torno dos Centros de Pesquisas Educacionais que surgem sob o ideário desenvolvimentista do país. Nesse contexto, a educação escolar deveria ser objeto de pesquisas científicas a partir dos mais avançados recursos das ciências sociais. Entretanto, segundo ressalta Cunha (2003, p. 462), o discurso desenvolvimentista difundido por intermédio dos Centros de Pesquisa contém "[...] proposiçóes desqualificadoras da família pobre e, de modo geral, de todas as parcelas da população que fossem de encontro ao modelo de sociedade idealizado."

Nas décadas de 1960-70, as teorias ditas crítico-reprodutivistas chamam a atenção para as relaçôes estabelecidas entre escola e família. No entanto, partiam de uma leitura determinista do sucesso ou fracasso escolar do estudante em função da origem social. A escola é colocada sob suspeição, conforme Weber (2009, p. 25), “[...] porque reprodutora da cultura dominante [...] ou reprodutora das relações sociais de produção, ou seja, das relaçôes sociais características do mundo capitalista [...]"

Dando continuidade à análise da relação escola e família com base na legislação do ensino, destacamos que a universalização do acesso à escola pública, que insere contingentes populacionais marginalizados da escolarização formal, tem início no regime militar com a Constituição de I967, que ampliou a obrigatoriedade do ensino de quatro para oito anos. Em 1971, a Lei no 5.692 reafirma essa ampliação da obrigatoriedade. A absorção das maiorias desestabilizou a cultura tradicional da escola e dos professores, que foram formados "[...] para um ensino restrito, formal e elitizado.” (CUNHA, 2005, p. 48) Nesse período, a escola pública não consegue lidar com as diferenças sociais e culturais dos estudantes das famílias pobres que nela ingressaram: generalizam-se problemas de indisciplina, reprovação e evasão escolar, rebaixando a qualidade do ensino. Em tal contexto, surgem a teoria da 'deficiência cultural' e a proposta da 'educação compensatória' para aplainar as 'deficiências' advindas das con- 
dições sociais dos filhos de famílias pobres, numa perspectiva que retoma o discurso desqualificador das famílias.

Ainda na década de 1970 houve, nos termos de Cruz e Santos (2008, p. 448), por parte da instituição escola, “[...] um movimento de convidar os pais para participar da vida escolar, instituindo o sentido de parceria, estruturado na delegação de atribuição, aos pais, ao cumprimento das aprendizagens escolares dos filhos." Para as autoras, essa estratégia camuflaria, de certa forma, a baixa da qualidade do ensino, a falta de condiçóes de trabalho dos professores, bem como o "[...] distanciamento do ideário de aluno idealizado pelos professores, e da realidade sociocultural das camadas em desvantagem social, que passaram a frequentar os bancos escolares [...]" (id.ib.) As autoras ainda enfatizam que, na década de I970, a diversidade da configuração de alunos da escola pública entra em conflito com o modelo único de escola, burguês e conservador, o que favorece a construção social do fracasso da escola pública. Por isso, nessa década, os especialistas entram como terceiro elemento na relação família-escola, solicitados que são a intervir nas dificuldades enfrentadas por essas duas instâncias. Porém, as mesmas autoras avaliam que o encaminhamento dos alunos aos especialistas, aliado à desvalorização da docência, social e economicamente, interfere nas posturas dos familiares, que assumem um tom de animosidade, desconfiança e distanciamento.

Na perspectiva de Cruz e Santos (2008), nos anos de 1980 as normas instituídas pelas escolas não contam com o respaldo das famílias de antes, já que foram estruturadas novas configuraçóes familiares. Assim, os antigos parâmetros adotados pelos professores provocam estranhamento na relação com essas famílias. $\mathrm{Na}$ perspectiva dos professores, "[...] a disciplina e a aprendizagem tornaram-se papéis da família, posto que seria a sua nova configuração que não mais permitia aos professores realizar, com eficiência, o seu papel." (op.cit., p. 449) Segundo essas autoras, na década de 1990 ocorre a massificação do diagnóstico de 'família desestruturada', de forma que a família é responsabilizada pelo fracasso dos educandos no âmbito da aprendizagem formal e pela não aquisição de regras básicas de convivência humana.

Diante do exposto, reafirmamos que a universalização da escola pública favoreceu o surgimento de uma nova configuração de alunos e, portanto, de famílias, que desestabilizou a cultura tradicional da escola. $\mathrm{Na}$ avaliação de Weber (2009, p.24), a escola "[...] continua referência so- 
cial na discussão a respeito de oportunidades e desigualdades educacionais no país, e pano de fundo de relações de rejeição, estigma, preconceito, violência, nela hoje observado." Trata-se, então, de pensar as famílias dos estudantes, que assumem configuraçóes diversas a partir da realidade dos tempos atuais. Afirmamos ainda que as famílias dos alunos estão relacionadas a condiçôes sociais e estilo de vida que traduzem os capitais cultural e social disponíveis.

\section{Metodologia}

Conforme Davies (2007), a confiabilidade de um Estado do Conhecimento depende, em parte, do recorte do universo a ser investigado, das fontes disponíveis e do seu tratamento. Para este balanço da produçáo do conhecimento investigamos teses e dissertaçôes, por reconhecermos a universidade e seus programas de pós-graduação como loci fundamental da pesquisa no Brasil. Privilegiamos os campos de conhecimento Educação, Psicologia e Ciências Humanas e Sociais devido à lacuna de revisão dessa produção que é apontada por diversos autores. (NOGUEIRA; ROMANELLI; ZAGO, 20II, 20I3; ZAGO, 20I2)

Para a localização das teses e dissertaçôes consultamos o banco de teses e dissertaçôes sobre a relação família-escola do grupo Observatório Sociológico Família-Escola da Universidade Federal de Minas Gerais (OSFE/UFMG); o banco de dados do Programa de Pós-Graduação em Família e Sociedade Contemporânea da Universidade Católica de Salvador (UCSal); e o banco de teses e dissertaçóes da Coordenação de Aperfeiçoamento de Pessoal de Nível Superior (CAPES). Selecionamos os trabalhos a partir de três campos: título, palavras-chave e resumo. Nesse processo, criamos dois bancos de dados: no primeiro, registramos o título da pesquisa, o nome da instituição e do Programa, a área de conhecimento, o ano de defesa e o nível de titulação - mestrado ou doutorado -, e identificamos os trabalhos pelo número de ordem em que foram localizados; no segundo, registramos, na mesma ordem, título da pesquisa, resumo e palavras-chave, 'salvamos' os trabalhos completos, eliminando aqueles indexados em mais de uma base de dados e que não resultavam de estudos empíricos. Destacamos que foram incluídos estudos nos quais 
a relação família-escola não era a questão central, mas que apresentavam contribuiçôes para a compreensão do tema como debate secundário.

O número de trabalhos localizados, um total de II2, tornaria a tarefa de leitura dos trabalhos na integra bastante complexa, razão pela qual nosso corpus de análise foram os resumos. Ferreira (2002) afirma que, ao lidarmos com um conjunto de resumos, podemos constatar que eles cumprem a finalidade que lhes está prevista em catálogos produzidos na esfera acadêmica: informam ao leitor, de maneira rápida, sucinta e objetiva, sobre o trabalho do qual se originam.

Para análise, utilizamos a Técnica da Análise de Conteúdo Categorial Temática, conforme Bardin (2002). Os II 2 resumos foram mapeados em relação às seguintes informações: objetivos, referenciais teóricos, opções metodológicas (campo empírico, participantes, instrumentos de coleta e análise) e resultados. Inicialmente, buscamos captar a unidade de significado de cada trabalho, submetendo-a posteriormente à classificaçáo segundo sua ênfase temática. Para o tratamento da variedade de assuntos específicos abordados, construímos categorias mais abrangentes que, longe de esgotarem as possibilidades de análise, permitiram uma visão geral das tendências temáticas.

\section{Resultados e discussáo}

Do total de trabalhos (I00\% = II2), 84\% (94) foram desenvolvidos em cursos de mestrado e I6\% (I8), de doutorado. Em relação às áreas de conhecimento, Educação concentra o maior número dos trabalhos $(77,7 \%$ - 87); na sequência aparecem as áreas de Sociais e Humanidades ( $15,2 \%=$ I7) e Psicologia $(7, \mathrm{I} \%=8)$.

Para fins analíticos, construímos três categorias temáticas (cf. Tabela I): I) Relação família-escola e estratégias educativas familiares, referente a trabalhos que identificam estratégias educativas das famílias para favorecer o sucesso escolar e/ou trajetórias escolares bem sucedidas de seus filhos (50,9\% = 57 estudos); 2) Relação familia-escola e fenômenos socio-escolares, relativa a pesquisas que tratam de assuntos relacionados ou à família ou à escola, porém não analisam a relação família-escola $(25 \%=28$ pesquisas); 3) Relação família-escola: fenômenos elou aspectos 
dessa relação, concernente a estudos que focalizam essa relação (24,I\% $=27$ trabalhos). Ressaltamos que a segunda e a terceira categorias concentram pesquisas centradas nos sujeitos e nos seus olhares, pois enfocam sentidos, significados, discursos, visōes, opiniōes, expectativas e/ ou representaçôes dos agentes que compóem a instituição escolar e/ou familiar em relação a determinados fenômenos.

\section{Tabela 1: Categorias Temáticas construídas a partir da análise dos resumos das Teses e Dissertaçóes (2004-2013)}

\begin{tabular}{c|c|c}
\hline Categorias & $f$ & $\%$ \\
\hline Relação família-escola e estratégias educativas familiares & 57 & 50,9 \\
\hline Relação família-escola e fenômenos escolar-sociais & 28 & 25 \\
\hline Relação família-escola: fenômenos e/ou aspectos dessa relação & 27 & 24,1 \\
\hline Total & 112 & 100 \\
\hline
\end{tabular}

Fonte: as autoras.

A primeira categoria, Relação família-escola e estratégias educativas familiares, foi organizada em três subcategorias: I) Trajetórias escolares; 2) Impactos na aprendizagem; e 3) Escolha de estabelecimentos de ensino. A maioria dos estudos tem problemáticas desenvolvidas a partir da Sociologia da Educação que, desde a década de I980, busca dar conta das esferas microscópicas da realidade familiar e já tem tradição de pesquisas na área.

$\mathrm{Na}$ subcategoria trajetórias escolares estão 44\% (25) dos trabalhos da categoria: abordam sucesso, longevidade e/ou mobilidade escolar. Foram classificados conforme os segmentos sociais nos quais se inserem as famílias: a) camadas populares - que concentra o maior número de estudos (I5); b) camadas médias; c) elites; d) mais de um dos segmentos: camadas populares e médias e camadas médias e superiores. Alguns estudos não enfocaram o segmento social, por conseguinte estão agrupados em 'outras trajetórias'. Esses trabalhos versam sobre percursos escolares em contextos específicos, tais como: internato, trajetórias escolares de professoras primárias e trajetórias de crianças adotadas. A subcategoria impactos na aprendizagem também reúne 44\% (25) dos trabalhos localizados na categoria, com pesquisas que apresentam diversos enfoques: a) impacto das práticas familiares de camadas populares no sucesso escolar de um modo geral ou 
relativo a um conhecimento específico; b) impacto das práticas das classes médias ou superiores de modo geral ou sobre um conhecimento específico; c) impactos dos fatores sociodemográficos de família de classe média sobre a escolarização dos filhos; d) ênfase nos impactos de práticas educativas familiares em atividades e/ou aprendizagens escolares de camadas sociais não especificadas; e) impacto do exercício da profissão docente dos pais na escolarização dos filhos; f) impacto da participação da família no processo educativo de alunos com deficiência visual; e h) impacto de vínculos familiares nas dificuldades de aprendizagem. Na subcategoria escolhas de estabelecimento de ensino agruparam-se I $2 \%$ (7) das pesquisas da categoria. Os estudos apresentam os seguintes enfoques: a) processo de escolha articulado com as estratégias das escolas, por exemplo, no sentido de preservação do sistema hierárquico; b) processo de escolha a partir das características dos grupos familiares (por exemplo, elites econômicas e culturais e docentes de uma escola pública); c) processo de escolha de estabelecimento de ensino específico por determinados grupos familiares, casos da escola Waldorf, escolhida por famílias de classes médias do Méier, bairro localizado na Zona Norte do Rio de Janeiro, por ser instituição católica.

A segunda categoria, Relação família-escola e fenômenos socio-escolares, congrega $25 \%$ (28) de todos os estudos. Como explicitamos, essas pesquisas tratam de assuntos relacionados ou à família ou à escola, porém não analisam a relação família-escola. Apesar disso, trazem contribuiçôes para a compreensão dessa relação. Os estudos destacam os seguintes tópicos: a) condutas comportamentais de estudantes de segmentos sociais ou escolares - setores populares, Educação Infantil e Ensino Fundamental; b) questóes específicas da Educação Infantil; c) inclusão escolar; d) violência infantil intrafamiliar; e) violência escolar; f) ingresso no I $^{\mathrm{o}}$ ano do Ensino Fundamental; g) avaliação das aprendizagens; h) dever de casa no contexto da avaliação; i) avaliação de escolas públicas; j) estresse, depressão e suporte familiar; k) educação baseada em valores; 1) alfabetização; $m$ ) paternidade gay; n) escola e/ou os saberes escolares; o) realidade familiar e/ou suas práticas.

A terceira categoria, Relação família-escola: fenômenos elou aspectos dessa relação, reúne 24,I\% (27) dos estudos. Eles focalizam a relação família-escola e enfatizam os seguintes aspectos: a) a própria relação famíliaescola; b) a relação família-escola com foco em um determinado fenômeno escolar-social, tais como: sucesso da escola, gestão escolar, visitas domici- 
liares, aprendizagem, repetência escolar, educação matemática, avaliação escolar, educaçáo de crianças de 4 a 6 anos, bilhetes como forma de comunicação entre família e escola, concepçóes sobre família e influências nas relaçóes família-escola; c) relação família-escola focalizando determinados grupos familiares: rurais, homoafetivos e candomblecistas; e d) relação família-escola e o estudo da família na formação inicial de pedagogos.

No que diz respeito aos referenciais teóricos referentes à família e à relação família-escola, dos II 2 resumos dos trabalhos localizados, apenas 37 mencionaram autores que estavam fundamentando o estudo. Em relação às opções metodológicas (campo empírico, participantes, procedimentos de coleta e análise), bem como aos resultados das pesquisas, também constatamos que muitas dessas informaçóes estavam ausentes dos resumos. Noutros termos, foram raros os resumos que apresentavam os estruturantes mínimos exigidos.

Em relação aos referenciais teóricos de família e/ou da relação famíliaescola, dos I9 autores referenciados duas ou mais vezes nove são franceses: Pierre Bourdieu, Bernard Lahire, Bernard Charlot, Daniel Thin, Michel de Certeau, François Dubet, François de Singly, Phillipe Ariès e Philippe Perrenoud. Os demais autores foram: Annette Laureau, Basil Bernstein, Heloisa Szymanski, Jailson de Souza e Silva, Lea Pinheiro Paixão, Maria Alice Nogueira, Maria José Braga Vianna, Nadir Zago, Norbert Elias e Paulo Freire. Conforme a Tabela 2, que evidencia os autores referenciados quatro vezes ou mais, os mais mencionados foram: Pierre Bourdieu (I9) e Bernard Lahire (I4). Na sequência, aparecem Bernard Charlot (5), Maria Alice Nogueira (5) e o francês Daniel Thin (4).

Tabela 2: Autores(as) referenciados(as) 4 vezes ou mais nos resumos dos estudos localizados

\begin{tabular}{c|c}
\hline Autores & Trabalhos \\
\hline Pierre Bourdieu & 19 \\
\hline Bernard Lahire & 14 \\
\hline Bernard Charlot & 5 \\
\hline Maria Alice Nogueira & 5 \\
\hline Daniel Thin & 4 \\
\hline
\end{tabular}

Fonte: as autoras. 
Quanto à metodologia, 65 dos resumos não referencia a abordagem da pesquisa. Dos que o fazem, a pesquisa é definida, na maioria (23), apenas como sendo de natureza qualitativa; outros acrescentavam informaçóes que remetiam ao método. Localizamos resumos que afirmavam ter realizado: estudo de caso (8), pesquisa com características etnográficas (4), pesquisa etnográfica do tipo estudo de caso (2), pesquisa qualitativa exploratória (2), qualitativa fenomenológica (I). Também foram utilizadas as seguintes expressóes para definir a metodologia: descritivo e exploratório (2); estudo descritivo (I). Alguns (4) definem a metodologia como sendo de caráter quantitativo e qualitativo.

No que se refere ao campo empírico em que foram desenvolvidos os estudos, muitos resumos não mencionaram a cidade e/ou o estado onde foi realizada a pesquisa. Coerentemente com a origem geográfica da produção, a maior parte das pesquisas foi realizada em cidades localizadas no estado de Minas Gerais (26). Na sequência, aparecem: São Paulo (I8), Bahia (I2), Rio de Janeiro (9), Santa Catarina (7), Rio Grande do Sul (4), Pernambuco (4) e Distrito Federal (2). No que diz respeito aos estudos que fizeram menção às instituiçôes escolares como loci da pesquisa empírica, constatamos que muitos resumos não fizeram menção ao nível federativo da escola, apenas mencionando ser pública (25) ou privada (23). Porém, a maior parte dos que referenciaram o nível federativo mencionou as escolas municipais (20). Destacamos que poucos estudos foram realizados em mais de uma realidade escolar. Também localizamos trabalhos realizados em universidades (I2), a maior parte sobre trajetórias escolares.

Em relação aos participantes das pesquisas, diversos segmentos envolvidos na relação família-escola figuraram como sujeitos de pesquisa dos estudos: estudantes, familiares (chamados genericamente de 'família', 'pais', 'mães” e/ou 'responsáveis'), professores, diretores, coordenadores e outros profissionais da escola. A maioria das pesquisas (59) foi realizada apenas com um desses segmentos; 52 estudos envolveram mais de um segmento e um resumo não mencionou os participantes da pesquisa. Conforme a frequência com que apareceram, podem ser assim organizados: familiares (67); estudantes (56); professores (43). Também foram participantes: diretores (I 2 ), coordenadores (IO) e outros profissionais da escola (4). 
Em relação aos procedimentos de coleta de dados, 6I trabalhos utilizaram mais de um instrumento, 44 referenciaram apenas um e 7 não mencionaram. Conforme mostra a Tabela 3, a entrevista é o instrumento mais utilizado nas pesquisas (88). Dos resumos que mencionaram o tipo de entrevista (58), a maioria (53) referenciou a entrevista semiestruturada. Os demais mencionaram a entrevista em profundidade (3), narrativa (I) e a clínica (I). Na sequência aparecem o questionário (30) e a observação (29). Sobre a observação, a maioria (22) mencionou os espaços e/ou atividades observados. A análise documental vem em seguida, referenciada em vinte e quatro (24) resumos. Em menor proporção, foram mencionados o grupo focal (o6) e o diário de campo (4). Mencionados em apenas dois resumos apareceram os seguintes instrumentos: associação livre de palavras e hierarquização, fotos e inventários.

Tabela 3: Instrumentos de produçáo de dados referenciados 2 vezes ou mais nos resumos dos estudos localizados

\begin{tabular}{c|c}
\hline Instrumentos de produção de dados & Trabalhos \\
\hline Entrevista & 88 \\
\hline Questionário & 30 \\
\hline Observação & 29 \\
\hline Análise documental & 24 \\
\hline Grupo focal & 06 \\
\hline Diário de campo & 04 \\
\hline Associação Livre e hierarquização & 02 \\
\hline Fotografias & 02 \\
\hline Inventários & 02 \\
\hline
\end{tabular}

Fonte: as autoras.

Quanto aos procedimentos de análise, dos II 2 resumos analisados apenas II os mencionaram. Desses resumos, cinco referiram a técnica de Análise de Conteúdo, sendo que um deles também utilizou o Statistical Package for Social Sciences (SPSS); três referiram-se a sistemas de categorias por meio de análise quantitativa-interpretativa dos dados; dois explicaram como realizaram a análise, mas não fizeram referência a uma técnica de análise específica; e um mencionou ter utilizado a Análise Textual Discursiva (ATD). 
Sobre os resultados dos trabalhos, ressaltamos que os apresentados nos resumos das pesquisas são bastante diferentes. Os estudos têm peculiaridades próprias que perpassam os trabalhos desde a construção do objeto de pesquisa até as contribuiçôes diversas marcadas pela área à qual o autor se vincula e pela literatura com a qual dialoga. Por isso, não traremos à baila os resultados de toda produçáo levantada. Traremos apenas daquelas pesquisas que se aproximam da problemática do estudo tratado neste artigo e na produçáo da tese.

Em relação aos resultados das pesquisas agrupadas na primeira categoria, resgatamos resultados de estudos localizados nas subcategorias que tratam de famílias pobres. Localizamos algumas pesquisas que tratam de trajetórias escolares de estudantes de famílias de camadas populares (I5). Parte delas evidenciou que as famílias, apesar de náo terem um alto capital escolar, participam das mais variadas formas na trajetória acadêmica de seus filhos, como os de Silva (2005) e Trad (2009). Estudos que versam sobre impactos de práticas de famílias de camadas populares no sucesso escolar de um modo geral reforçaram que a omissão parental é um mito. Alguns como Poncio (20I0) e Tertuliano (20I0) ressaltaram ainda o forte papel desempenhado pelas mães nesse acompanhamento. Estudos que tratam dessas estratégias focalizando um conhecimento específico apontaram, entre outros elementos, para a quebra de mitos sobre a relação de famílias de meios populares com a leitura (CARVALHO, 2005) e que uma leitura literária competente está vinculada não à camada social, mas à singularidades dos sujeitos. (MAZZONETTO, 2009)

No que diz respeito aos estudos localizados na segunda categoria, destacamos os que enfatizam os sentidos atribuídos à família e/ou a suas práticas (4). Telles (2006) analisou as práticas educativas da família contemporânea a partir das representaçôes dos pais sobre a educação que transmitiram aos seus filhos e dos filhos sobre a educação que receberam dos seus pais, e revelou que as relações se tornaram mais igualitárias. Lazzarini (20I2) pesquisou concepçôes de adolescentes de escolas privadas e públicas sobre a família na contemporaneidade e os resultados apontaram que os adolescentes de ambas as escolas vivenciam realidades familiares diversas, mas apresentam a concepçáo de família nuclear. Fialho (2012) analisou a efetivação da proposta de tempo integral da Secretaria Estadual de Educação de Minas Gerais e debruçou-se sobre as percepçóes de alunos 
adolescentes sobre a escola e a família. Os resultados mostraram que a proposta ocorre pela diversificação das famílias pobres e as alteraçôes nos papéis sociais dentro e fora de casa. Ribeiro (20II) investigou as representações de família construídas por crianças do Recife e constatou que elas representam a família de forma idealizada e positivada.

Sobre os estudos agrupados na terceira categoria, destacamos os resultados das pesquisas de Souza (2010), Cruz (2008), Alves (2012) e Leal (20II). Souza (20Io) enfocou a participação da família na escola e suas interfaces com a gestão em duas escolas da Rede Municipal do Recife. Os resultados indicaram que a participação da família existe e está relacionada às características do grupo social que constitui a escola. Cruz (2008) pesquisou as concepçóes que docentes dos anos iniciais do Ensino Fundamental de uma escola pública constroem sobre a família e sua influência na relação escola-família. Os resultados revelaram que a escola promove um discurso que defende a parceria com as famílias, mas na prática ignora a diversidade que elas apresentam. Alves (20I2) analisou os sentidos e significados atribuídos às famílias por professores da Educação Infantil e a importância da relação família-escola para o trabalho docente. A participação das famílias é vista como importante, mas a ausência de um currículo que trate dessa questão dificulta a relação. Leal (201 I) focalizou a relação família-escola no âmbito da formação inicial de pedagogos, problematizando-a a partir do (des)conhecimento de estudos desenvolvidos sobre a família nessa formação inicial. A autora afirma ter constatado que há conscientizaçáo quanto à relevância do estudo sobre família no itinerário formativo e o reconhecimento da necessidade de se desenvolver um estudo mais sistematizado sobre a temática.

\section{Consideraçóes finais}

Este levantamento não esgota a produção veiculada sobre a relação família-escola no Brasil, pois além de o estudo estar circunscrito a um período estabelecido (2004-2013), reconhecemos que existem outras fontes e outros produtos importantes do processo de conhecimento náo cobertos neste estudo. Trata-se, porém, de um esforço para mapear essa produção considerando diferentes campos disciplinares, uma lacuna apontada por 
diversos autores. Assim, consideramos que os resultados que apresentamos trazem contribuiçôes sobre a produção científica nos últimos anos em relação à temática no Brasil.

Os resultados apresentados por algumas pesquisas (RIBEIRO, 20I I; CRUZ, 2008; ALVES, 20I2) apontaram para certa resistência a configuraçôes familiares diferentes da tradicional. Aliás, os resultados das pesquisas de Cruz (2008) e Alves (2012) apontaram mais: que os sentidos ou concepçôes dos professores sobre a família influenciam a relação família e escola e/ou o trabalho docente.

Localizamos, ainda, resultados de pesquisas que desconstroem a ideia generalizada de que as famílias de alunos de escola pública são desestruturadas. As pesquisas que focalizaram o sucesso escolar de trajetórias de estudantes de famílias de camadas populares apontaram que essas famílias, apesar de não terem um alto capital instrucional, participam das mais variadas formas na trajetória acadêmica de seus filhos, como os de Silva (2005) e Trad (2009). Outros estudos reforçaram que a omissão parental dessas famílias é um mito. Os estudos reunidos com essa mesma preocupação, de modo geral, revelaram que os familiares investem na educaçáo dos filhos e alguns ressaltaram o forte papel desempenhado pelas mães nesse acompanhamento. (PONCIO, 20I0; TERTULIANO, 20Io)

Pelo que aqui foi exposto, reiteramos a necessidade de pesquisas sobre a temática na área da Educação, pois há ainda vários aspectos a serem aprofundados. Dentre esses aspectos, reiteramos a necessidade de estudos que se dirijam ao professor no sentido de analisar e compreender suas representaçóes sociais das famílias dos seus estudantes, que constituiu o foco de nossa pesquisa de doutorado em Educação e foi uma das bases para a construção deste artigo. Como vimos, não localizamos estudos preocupados em compreender essas representaçóes sociais e como eles orientam as práticas dos docentes. Defendemos que a intenção de ouvir os professores para conhecer o que dizem, pensam, sentem e fazem é positiva, já que se pretende descobrir, juntamente com eles, os caminhos mais efetivos para se garantir um ensino de qualidade que reverta para uma aprendizagem significativa a todos os alunos da escola pública.

Por fim, destacamos que este Estado da Arte apontou a importância de os pesquisadores estarem atentos aos elementos necessários à escrita dos resumos, que envolvem, por exemplo, a descrição do percurso metodoló- 
gico. Como vimos, quase a totalidade dos resumos náo apresentou procedimentos nem instrumentos de análise de dados utilizados. A ausência de informaçóes dificulta visualizar o ciclo da pesquisa, o que repercute de modo direto e negativo na compreensão dos achados.

Embora pesquisadores - como Megid (1999) - já tenham questionado a natureza do material com o qual trabalhamos, consideramos, como Ferreira (2002), o resumo um gênero do discurso da esfera acadêmica que deve ser lido pelos elementos que o constituem: conteúdo temático, estrutura composicional e estilo verbal.

Portanto, para responder à finalidade de divulgar com mais abrangência os trabalhos produzidos na esfera acadêmica, os resumos precisam ser objeto de elaboração cuidadosa. Destacamos, inclusive, que indexadores e qualificadores de produção científica têm reforçado a necessidade de os resumos de trabalhos acadêmicos serem mais qualificados. Portanto, é necessário que os pesquisadores, na produção dos resumos, contemplem os elementos que constituem esse gênero do discurso, pois eles são elementos básicos das pesquisas que vão ampliar os horizontes do debate acadêmico.

\section{Referências}

ALVES, Angélica Aparecida Curvelo. Sentidos e significados do educador da infância sobre a família. 20I2. I66f. Dissertaçáo (Mestrado em Educaçáo) - Pontifícia Universidade Católica de São Paulo, São Paulo, 2012.

ALVES-MAZZOTTI, Alda Judith. A "revisão bibliográfica" em teses e dissertaçôes: meus tipos inesquecíveis - o retorno. In: BIANCHETTI, Lucídio; MACHADO, Ana Maria Netto (Org.). A buissola do escrever: desafios e estratégias na orientaçấo e escrita de teses e dissertaçóes. São Paulo: Cortez, 2002, p. 25-44.

BARDIN, Laurence. Análise de conteúdo. Lisboa: Ediçóes 70, 2002. 223p.

BRASIL. Constituição. Constituição da República Federativa do Brasil de 1967. Disponível em: <http://www.planalto.gov.br/ccivil_03/constituicao/constituicao67. htm>. Acesso em: 05 maio 2014.

BRASIL. Lei no 5.692, de II de agosto de 197I. Fixa diretrizes e bases para o ensino de $\mathrm{I}^{\circ} \mathrm{e} 2^{\circ}$ graus, e dá outras providências. Diário Oficial [da] República Federativa do Brasil, Brasília, DF, I2 ago. 1971. Disponível em: <http://www.planalto.gov.br/ ccivil_03/leis/L5692.htm>. Acesso em: Io maio 2014. 
CAMPOS, Alexandra. Família e escola: um olhar histórico sobre as origens dessa relação no contexto educacional brasileiro. Vertentes (UFSJ), v. I9, p. 6I-7I, 20 II. Disponível em: <http://www.ufsj.edu.br/portal2 repositorio/File/vertentes/v.\%2019\%20 n.\%202/Alexandra Campos.pdf>. Acesso em: 08 out. 2015.

CARVALHO, Silvio Roberto Silva. A influência de familias de camadas populares na formação de filhos leitores. 2005. I8o f. Dissertação (Mestrado em Família na Sociedade Contemporânea) - Universidade Católica de Salvador, Salvador, 2005.

CRUZ, Antônio Roberto Seixas da. A relação escola e famílias: concepçóes elaboradas por agentes educadores no âmbito de uma escola pública dos anos iniciais do Ensino Fundamental. 2008. 202f. Tese (Doutorado em Educação) - Universidade Federal da Bahia, Salvador, 2008.

CRUZ, Fátima Maria Leite; SANTOS, Maria de Fátima de Souza. A relação famíliaescola: fronteiras e possibilidades. Revista de Educação Pública, Cuiabá, v. I7, n. 35, p. 443-454, 2008. Disponível em: <http://periodicoscientificos.ufmt.br/ojs/index.php/ educacaopublica/article/view/500/426>. Acesso em: 05 nov. 2015.

CUNHA, Elizabete. Gestão municipal participativa e o papel da escola. São Paulo: Annablume, 2005. I30p.

CUNHA, Marcus Vinicius da. A escola contra a família. In: LOPES, Eliane Marta Teixeira; FARIA FILHO, Luciano Mendes; VEIGA, Cynthia Greive (Org.). 500 anos de educação no Brasil. 3 ed. Belo Horizonte: Autêntica, 2003. p.447-468. (Org.). Familia, escola e juventude: olhares cruzados Brasil-Portugal. Belo Horizonte: Editora UFMG, 2012. p. 09-19. DAVIES, Philip. Revisôes sistemáticas e a Campbell Collaboration. In: THOMAS, Gary; PRING, Richard (Org.). Educação baseada em evidências: atualização dos achados científicos para a qualificação da prática pedagógica. Porto Alegre: Artmed, 2007. p. 3I-43.

FARIA FILHO, Luciano Mendes de. Para entender a relação escola-família: uma contribuição da história da educação. São Paulo em Perspectiva [online]. São Paulo, v.I4, n.2, p.44-50, Jun. 200o. Disponível em: <http://www.scielo.br/scielo. php?script=sci_arttext $\&$ pid $=$ Soro $2-88392000000200007 \& \operatorname{lng}=$ en $\& n r m=i s o \& t \operatorname{lng}=p t>$. Acesso em: 05 nov. 2015.

FERREIRA, Norma Sandra de Almeida. As pesquisas denominadas "Estado da Arte". Educação \& Sociedade, ano XXIII, no 79, Agosto/2002, p. 257-272.

FIALHO, Gleicilene Nazare. Um estudo com alunos adolescentes do Projeto Escola de Tempo Integral (Proeti) em Betim-MG: Interpretando suas percepçóes sobre a família e a escola. 20I2. I 46 f. Dissertação (Mestrado em Educação) - Pontifícia Universidade Católica de Minas Gerais, Belo Horizonte, 2012. 
GOLDANI, Ana Maria. As famílias no Brasil contemporâneo e o mito da desestruturação. Cadernos Pagu, Núcleo de Estudos de Gênero-Pagu/Unicamp, I993, p.67-I Io. Disponível em: <http://periodicos.sbu.unicamp.br/ojs/index.php/cadpagu/ article/view/I68I/I664>. Acesso em: 05 ago. 2013.

LAZZARINI, Renata Alvares da Silva. As concepçóes de adolescentes sobre a familia na contemporaneidade. 20I2. I64 f. Dissertação (Mestrado em Educação). Centro Universitário Moura Lacerda, São Paulo, 2012.

LEAL, Teresa Cristina Merhy. O estudo da familia no itinerário formativo do pedagogo/ professor: concepçóes de docentes e formandos de um Curso de Licenciatura em Pedagogia da Cidade de Salvador. 20I I. 203f. Dissertação (Mestrado em Família na Sociedade Contemporânea) - Universidade Católica de Salvador, Salvador, 20 I I.

MAZZONETTO, Silvia Maria Leme do Prado Cascione. Estratégias de aquisição do capital literário por estudantes de letras originários de camadas populares. 2009. I50f. Dissertação (Mestrado em Educação) - Pontifícia Universidade Católica de São Paulo, São Paulo, 2009.

MEGID, Jorge Neto. Tendências da pesquisa acadêmica sobre o ensino de ciências no nível fundamental. I999. 365f. Tese (Doutorado em Educação) - Universidade Estadual de Campinas - Faculdade de Educação, Campinas, I999.

NOGUEIRA, Maria Alice. Família e escola na contemporaneidade: os meandros de uma relação. Educação e Realidade, v. 31, n. 2, p. I55-170, jul./dez. 2006. Disponível em: <http://seer.ufrgs.br/educacaoerealidade/article/view/6850>. Acesso em: 02. Ago. 2013 .

NOGUEIRA, Maria Alice; ROMANELLI, Geraldo; ZAGO, Nadir (Org.). Família e escola: trajetórias de escolarização em camadas médias e populares. 6. ed. Petrópolis, RJ: Vozes, 20I I. I83p.

Família e escola: novas perspectivas de análise. Petrópolis, RJ: Vozes, 2013.

$338 \mathrm{p}$.

PONCIO, Gilberto Valdemiro. Relação família-escola na EJA: Estratégias educativas familiares e trajetórias escolares em camadas populares. 20Io. Dissertação (Mestrado em Educação). Universidade Regional de Blumenau, Blumenau.

RIBEIRO, Fernanda Siqueira. "Família tem que ter pai e mãe": Representaçôes sociais de família por crianças na cidade de Recife. 20 I I. 22 f. Dissertação (Mestrado em Psicologia) - Universidade Federal de Pernambuco, Recife, 20 I I.

ROMANOWSKI, Joana Paulin; ENS, Romilda Teodora. As pesquisas denominadas do tipo "Estado da Arte” em Educação. Revista Diálogo Educacional, vol. 6, núm. septiembre-diciembre, 2006, p. 37-50. 
SILVA, Fabiana Cristina. Trajetórias de longevidade escolar em famílias negras e de meios populares (Pernambuco, I950-I970). 2005. 243f. Dissertação (Mestrado em Educação) Universidade Federal de Pernambuco, Recife, 2005.

SOUZA, Priscila Ximenes de. A participação da família na escola e suas interfaces com a gestão: Caminhos possíveis em instituiçóes da Rede Municipal de Ensino do Recife. 20I0. I37f. Dissertação (Mestrado em Educação) - Universidade Federal de Pernambuco, Recife, 20 Io.

TELLES, Rosana Rocha Gusmão da Silva. Mudanças nas práticas educativas da família contemporânea e suas relaçóes com a escola. 2006. I28 f. Dissertação (Mestrado em Educação) - Universidade Estácio de Sá, Rio de Janeiro, 2006.

TERTULIANO, Maria Jussara dos Santos. Famílias de camadas populares e escola: discursos e práticas na escolarização dos filhos. 20I0. 223f. Dissertação (Mestrado em Educação) - Universidade Federal de São João Del Rei, São João Del Rei, 20 ı.

TRAD, Márcia Fontoura. O sucesso escolar de alunos dos meios populares na década de 60, no Colégio Estadual de Minas Gerais: Reconstruindo as suas Trajetórias. 2009. I34 f. Dissertação (Mestrado em Educação) - Universidade Federal de Minas Gerais, Belo Horizonte, 2009.

VOSGERAU, Dilmeire Sant'Anna Ramos; ROMANOWSKI, Joana Paulin. Estudos de revisão: implicações conceituais e metodológicas. Revista Diálogo Educacional, Curitiba, v. I4, n. 4I, p. I65-I89, jan./abr. 2014.

ZAGO, Nadir. A relação escola-família nos meios populares: apontamentos de um itinerário de pesquisas. DAYRELL, Juarez; NOGUEIRA, Maria Alice; RESENDE, José Manuel; VIEIRA, Maria Manuel (Org.). Familia, escola e juventude: olhares cruzados Brasil-Portugal. Belo Horizonte: Editora UFMG, 2012. (p. I32-I50)

WEBER, Silke. Desigualdades sociais e escola: alguns aspectos a considerar. In: SCOTT, Parry; LEWIS, Liana; QUADROS, Marion Teodósio de (Org.). Gênero, diversidade e desigualdades na educação: interpretaçóes e reflexôes para formação docente. Publicaçóes Especiais do Programa de Pós-Graduação em Antropologia/ FAGES: Editora Universitária, Recife, 2009. p. 23-40.

Recebido em 26 jul. 2017 / Aprovado em 28 mai. 2018

Para referenciar este texto

LIMA, A. M.; MACHADO, L. B. Relação família-escola: o estado da arte na pós-graduação brasileira. EccoS - Revista Científica, São Paulo, n. 46, p. I49-I70. mai./ago. 20I8. Disponível em: <https://doi.org/I0.5585/EccoS.n46.7624>. 